\title{
EFFECT OF MULTIPLE USE AND STERILIZATION OF SINGLE-STEP POLISHING SYSTEMS ON THE SURFACE ROUGHNESS OF RESIN COMPOSITE
}

\author{
Marwa Mahmoud Ashour ${ }^{*}$, Mohammed Nasser Mohammed ${ }^{* *}$ and Khaled Aly Nour ***
}

\begin{abstract}
Aim: To evaluate the effect of multiple use and sterilization of Single-Step polishing tips on the surface roughness of resin composite.

Materials and Methods: Eighty Nano-filled resin composite discs were prepared and cured against Mylar strip. Except for the control group, samples were wet ground against 600-grit SC paper, then divided into 3 groups $(n=25)$, Group D (Dimanto ${ }^{\circledR}$ - VOCO), Group G $\left(\right.$ PROGLOSS $^{\mathrm{TM}}$ - KaVo Kerr), and Group O (OptraPol ${ }^{\circledR}$ - Ivoclar Vivadent). Five tips from each system were autoclaved and used for sample polishing, and this process was repeated for 5 successive Reuse/ Sterilization cycles (S1 - S2 - S3 - S4 - S5). Samples were scanned using SEM, scans were analysed by Gwyddion 2.53 Image Analysis Software to attain surface roughness average $\mathbf{R}_{\mathbf{a}}$ data, which were statistically analysed by two-way ANOVA and Tukey Post Hoc test.
\end{abstract}

Results: Single-step polisher system, reuse/sterilization cycles and their interaction were found to have a statistical significant effect on the $\mathbf{R}_{\mathrm{a}}$ of the tested groups. Control group had the least $\mathbf{R}_{\mathrm{a}}$. All S1 Groups and two of S2 groups, showed higher $\mathbf{R}_{\mathrm{a}}$ without statistically significant difference between them or between them and the control. The following cycles showed a progressive increase in $\mathbf{R}_{\mathrm{a}}$ values, with GS4, GS5, DS5, and roughened groups, showing the highest $\mathbf{R}_{\mathrm{a}}$ without statistically significant difference between them.

Conclusion: Single-step reusable polishing tips can polish resin composite back to matrix-set $\mathbf{R}_{\mathrm{a}}$ values within the first and second reuse/sterilization cycles, afterwards the tips' polishability decreases significantly and becomes system dependent.

KEYWORDS: Dental Polishing, Equipment Reuse, Composite Resins, Sterilization, Surface Roughness.

\footnotetext{
* B.D.S. 2013, Faculty of Dentistry, Ain Shams University, Cairo, Egypt.

** Lecturer at Faculty of Dentistry, Ain Shams University, Cairo, Egypt.

*** Assistant Professor at Faculty of Dentistry, Ain Shams University, Cairo, Egypt.
} 


\section{INTRODUCTION}

The resin composite restorations requires finishing and polishing after placement. This procedure is important to get rid of any overhanged or excess composite material, to restore the occlusion and morphology of the surface and even more importantly to remove the matrix-rich surface layer. Unpolished resin composite surfaces that are rich in organic matrix are relatively unstable, as they have a stickier and softer consistency. This superfacial layer needs to be removed by polishing to avoid accelerated clinical wear. ${ }^{1}$ Finishing of a restoration is defined as the gross reduction of excess material to achieve the ideal morphology and optimal function. ${ }^{2-4}$ While, polishing is defined as the reduction of roughness and scratches created during the finishing of the composite resin. ${ }^{4}$ Finishing and polishing instruments are mainly used to induce intentional, selective, and controlled wear of dental restorative material surfaces. Wear is a phenomenon of cumulative surface damage in which material is removed from a body as small debris particles, primarily by mechanical processes (adhesion, abrasion, surface fatigue, and tribochemical reactions). ${ }^{4}$ Abrasive-wear modes are classified as: a) two-body abrasion and b) threebody abrasion. In a two-body mode, the abrasive particle is solidly attached to the substrate, which is how most dental polishing devices operate.

In fact, several factors affects the final surface polish and roughness values of the restorations, including:

a) Resin composite material intrinsic factors (type of matrix monomers, degree of polymerization and size of fillers) $)^{5}$.

b) Polishing system selection (tip material, abrasive type, size $^{6}$ and geometry).

c) Polishing system manipulation (Pressure, Speed, Duration, Type of motion, Immediate/ late and wet/dry).

\section{d) Disinfection and sterilization protocol.}

The selection of the most efficient polishing system among the different types available in the market remains challenging. Comparing between multi-steps and single-step polishing systems, it was found that introducing single step polishing systems offered dental professionals the great advantage of less chair time, more convenience, lower chances of cross contamination, and most importantly having the same effectiveness of multi-step systems ${ }^{3,7-9}$. Yet, most of the released single-step polisher were single-use tips in the beginning, causing feasibility issues and driving the manufacturers to produce the recent types of multi-use single-step polishers. Multi-use systems are attractive for several reasons, especially that their disposal after only one use is considered an unnecessary waste and that they can be safely sterilized and reused. Still, once the tip fine edges have been degraded and/or the flexibility of the elastomeric substrate has been lost from chemical or heat sterilization, the polisher tips shape changes and their efficiency mostly decreases. And based on the previously mentioned description of the two-body mode abrasive-wear pattern ${ }^{4}$, followed by the reusable elastomeric polishing instruments, the friction on polishing tip surface causes gradual loss of the abrasive particles exposing the elastomeric matrix and accelerating its wear and deterioration.

Additionally, these multi-use systems have an unquestionable need to go through multiple disinfection and sterilization cycles in order to be used efficiently between different patients. It's important to choose the best disinfection /sterilization method in regard to the antimicrobial efficiency and the amount of damage they may cause to the polishing tips \& points used. Autoclaving has always been considered the best method of sterilization for dental instruments. ${ }^{10,11}$ At the sterilization chamber the steam is introduced at a very high pressure and temperature, ${ }^{11}$ In order to study the effect of this physical challenges on the used rubber tips, studies 
of the plasticity* and Plasticity Retention Index $(\mathrm{PRI})^{* *}$ of silicon rubbers and other elastomers found that the long term performance of silicones is generally excellent. Although exposure to steam at high pressure, as well as ageing in closed systems can lead to degradation via a hydrolysis reaction, ${ }^{12}$ decreasing their PRI. Yet this effect was found to be highly dependent on the type of used polymer. ${ }^{13}$ In another word, polymers used in the manufacturing of polishing tips may deteriorate as a result of chemical, thermal, and physical factors. These factors may act synergistically, accelerating the deterioration process. The deterioration affects the main backbone chain, side groups, cross-links, and the original molecular arrangement of those polymers ${ }^{14}$, resulting on less plasticity, friction tolerance, and once again faster deterioration of the polishing tip. In fact, several studies with controversial results were performed to assess the effect of the multiple use and sterilization on the polishing instruments. Where some have revealed a decline in overall efficacy of the tips, ${ }^{15,16}$ and problems like reduced polishing performance even after the very first use compared to a new polishing tips. ${ }^{16}$ In contrast to other earlier studies of Krejci et al. ${ }^{17}$ and Tate $\mathrm{WH}$ et al. ${ }^{18}$ which stated that the performance of the finishing and polishing products was not affected by the autoclave sterilization. A claim that many dental companies alleged about their polishing instruments, even though the lack of evidence based data about this issue, which was the primary motive behind conducting this study.

\section{MATERIALS AND METHODS}

In total, 80 Nanofilled resin composite discs (Filtek $^{\mathrm{TM}}$ Z350 XT, 3M ESPE, St. Paul, MN, USA) (A2 shade) (table 1), were prepared using split Teflon mold (5mm in diameter and $2 \mathrm{~mm}$ in depth). Resin composite was deposited in a single layer inside the mold using a double flat instrument. The upper surface of the mold was covered with a transparent matrix (Mylar strip) and a glass slab was pressed on to ensure the surface flatness and smoothness, then removed before curing by a 3M ESPE Elipar Deep Cure Light Cure device with the intensity of $1400 \mathrm{~mW} / \mathrm{cm}^{2}$ for 20 seconds according to the manufacturer instructions. The tip of the device was placed in touch with the Mylar strip perpendicular to the composite surface. The intensity of the light output of the device was monitored by the radiometer device among each 5 samples. Except for control group $(n=5)$, samples were wet ground against 600 grit SC paper (equivalent to yellowcoded finishing stone) for $30 \mathrm{sec}$. After which they were divided into 3 main groups $(n=25)$, Group D (Dimanto $^{\circledR}$ - VOCO), Group G (PROGLOSS ${ }^{\mathrm{TM}}$ KaVo Kerr), and Group O (OptraPol ${ }^{\circledR}$ - Ivoclar Vivadent) (table 1). Five disk-shaped polishing tips from each system were sterilized and used for resin composite sample polishing (30 secs, following the manufacturer instruction), and this process was repeated for 5 successive Reuse and Sterilization cycles (S1 - S2 - S3 - S4 - S5) on 5 different samples each time. Samples were polished with a low-speed handpiece (NSK Dental Low Speed Handpiece EX-203 Set Japan) at 10,000 RPM speed, under copious water spray for 30 seconds to avoid excessive heat generation according to manufacturer instructions. For optimum standardization of the applied pressure a specially fabricated Load Fixation Device was used where the contra was hanged freely above the samples under its own weight. Each of the used polishing tips were reprocessed by mechanical cleaning for

\footnotetext{
* Plasticity of Elastomers: Susceptibility to, and retentivity of deformation', and also 'the degree of flow which takes place under given conditions of temperature and pressure.

** Plasticity Retention Index PRI: The PRI test consists in measuring the Wallace Plasticity of the raw rubber before and after ageing for 30 minutes at $140{ }^{\circ} \mathrm{C}$, the aged plasticity being expressed as a percentage of the unaged.
} 
10 minutes in ultrasonic device (MCS, Digital Ultrasonic cleaner, CD-4860, 6000ml) filled with distilled water. Then they were thoroughly rinsed under running water using a plastic bristle brush and dried with a fresh, clean lint-free cellulose tissue following their manufacturer instructions. After that polishing tips were sterilized using steam autoclave (Ritter M9 Ultraclave ${ }^{\circledR}$, Automatic Sterilizer, MIDMark, USA) for 30 minutes, at a temperature of $134^{\circ} \mathrm{C}\left(273^{\circ} \mathrm{F}\right)$, and throw a 15 minutes' vacuumdrying cycle, after which sterilized tips got to be used for the next polishing cycle.

After polishing the resin composite samples according to their assigned groups, they were scanned using Scanning Electron Microscope (SEM) at 3000x magnifications using backscattered electron detector (BSED). After which the scan of each sample was analysed using Gwyddion $\mathbf{2 . 5 3}$ software (SPM data visualization and analysis tool, supported by the Czech Metrology Institute, 2019) in order to gain the surface roughness average $\mathbf{R}_{\mathbf{a}}$ values that were statistically analysed by two-way ANOVA and Tukey Post Hoc test. Representative samples from each group were randomly selected to qualitatively evaluate the resin composite samples surface (Fig. 1,2).

Table (1) Materials Ingredients \& specifications

\begin{tabular}{|c|c|c|}
\hline Material & Composition & Manufacturer \\
\hline Dimanto® & - Diamond-impregnated silicone polisher & VOCO, US \\
\hline PROGLOSS ${ }^{\mathrm{TM}}$ & - Diamond impregnated formulation. & KaVo Kerr Group \\
\hline OptraPol $^{\circledR}$ & $\begin{array}{l}\text { Polishers are made of light-grey polishing material with a red core without } \\
\text { polishing fun-tion. } \\
\text { - The light-grey polish-ing material consists of synthetic rubber and diamond } \\
\text { particles. } \\
\text { - The red core material contains synthetic rub-er, aluminum oxide, iron oxide and } \\
\text { Irgazin red. The handles are made of stainless steel. }\end{array}$ & Ivoclar Vivadent \\
\hline $\begin{array}{ll}\text { Filtek }^{\text {TM }} & \text { Z350 } \\
\text { XT } & \end{array}$ & $\begin{array}{ll}\text { - } & \text { Matrix: Bis-GMA, UDMA, Bis-EMA, TEGDMA } \\
\text { - } & \text { Filler, zirconia/silica } \\
\text { - } & \text { Nanofillers of silicon ( } 5-75 \mathrm{~nm}) \text {, } \\
\text { - } & \text { Zircon / silicon nano- clusters (0.6-1.4 um) } \\
\text { - } & \text { Nanofiller } 78.5 \% \text { by wt, } 59.5 \% \text { vol. }\end{array}$ & $\begin{array}{l}\text { (3M ESPE, St Paul, } \\
\text { MN, USA) }\end{array}$ \\
\hline
\end{tabular}

Bis-GMA: Bisphenol A diglycidimethacrylate: UDMA: Urethane dimethacrylate; EMA: ethylmethacrylate; TEGDMA: triethylene glycol dimethacrylate. 


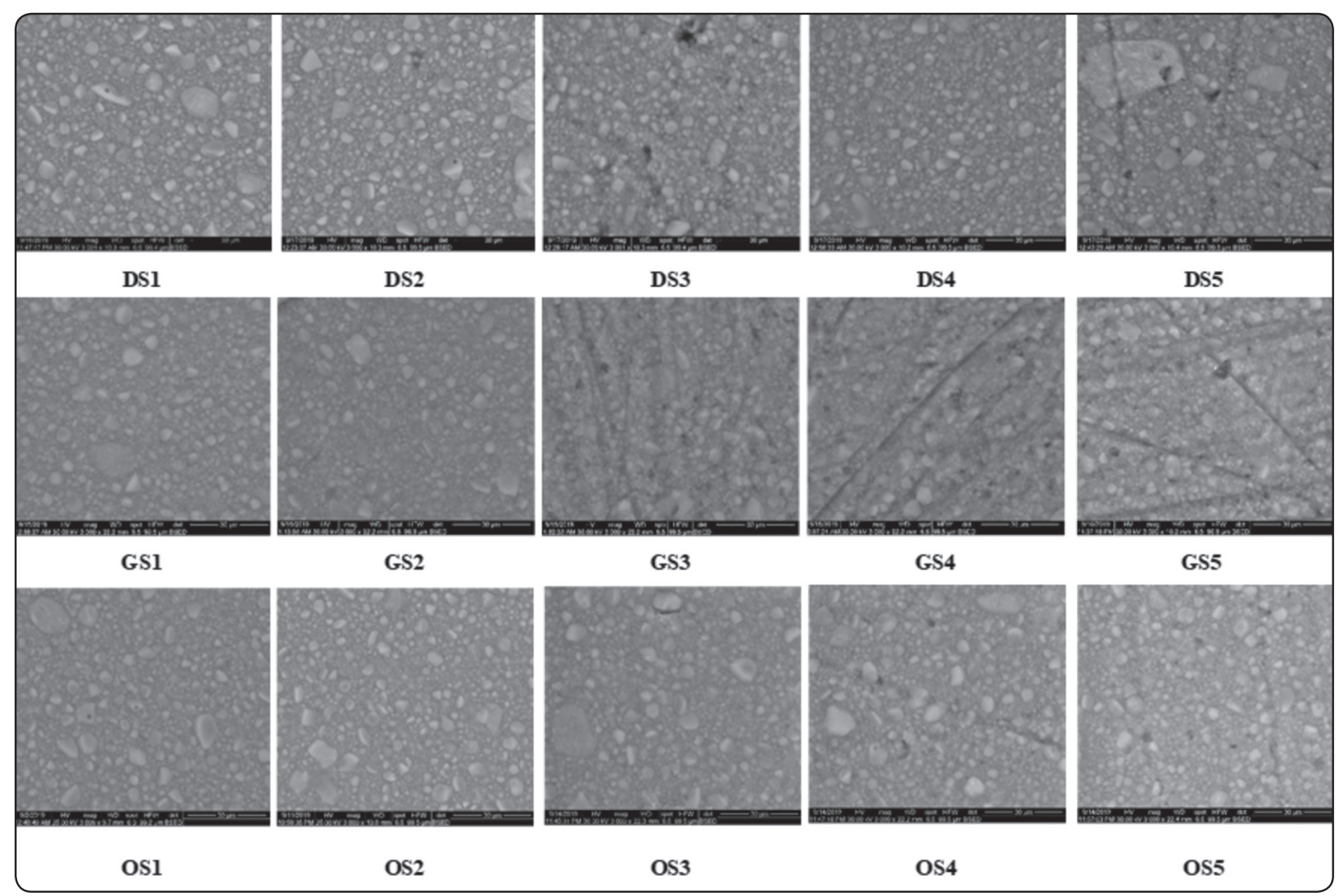

Fig. (1) SEM scans of representative samples.

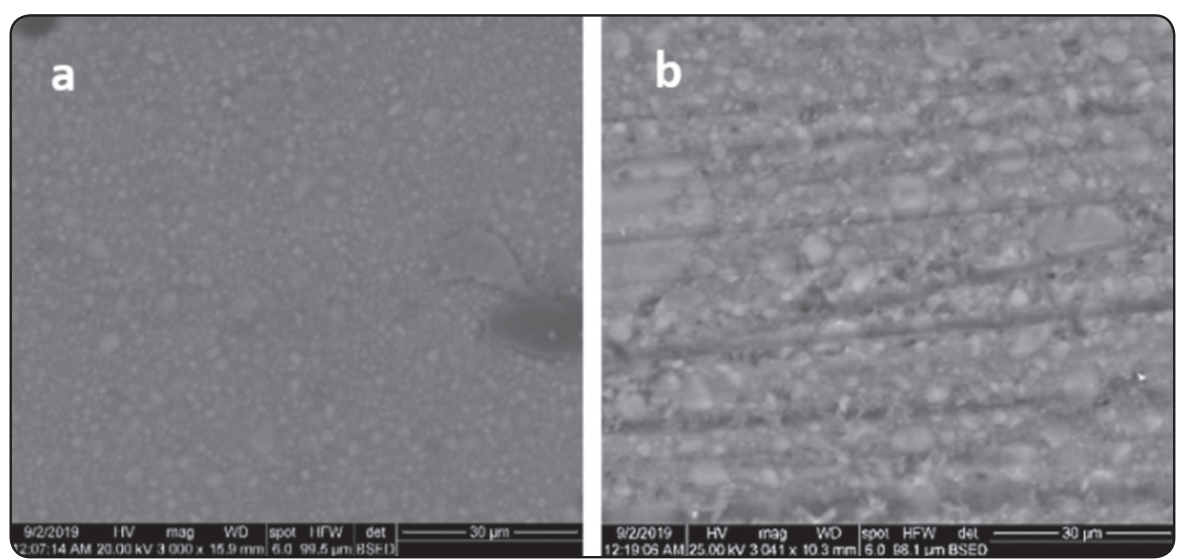

Fig. (2) Scanning electron microscope photograph of Filtek ${ }^{\mathrm{TM}} \mathrm{Z} 350 \mathrm{XT}$ composite resin surface at 3000x magnification. a. Control group (Mylar strip formed surface) $\mathrm{R}_{\mathrm{a}}=71.6 \mathrm{~nm}$. b. Roughened group (Wet grinded against $600 \mathrm{SC}$ paper) $\mathrm{R}_{\mathrm{a}}=132.6 \mathrm{~nm}$. 


\section{RESULTS}

Tow-way ANOVA followed by Tukey HSD Post-Hoc test revealed that the Single-Step Polisher system and the Reuse and Sterilization cycle as well as the Polisher system / Reuse and Sterilization Cycle Interaction were found to have a statistical significant effect on the surface roughness average $\mathbf{R}_{\mathrm{a}}$ of the tested groups. Regardless of the Reuse and Sterilization Cycle, OptraPol Group gave the least statistically significant $\mathbf{R}_{\mathbf{a}}$ followed by the Dimanto Group, then the ProGloss Group. While, regardless to the Polisher system $\mathbf{S 1}$ and $\mathbf{S 2}$ Groups gave the least statistically significant $\mathbf{R}_{\mathrm{a}}$ with no statically significant difference between them. Followed by the $\mathbf{S 3}$ Group, then $\mathbf{S} \mathbf{4}$ Group, and finally $\mathbf{S 5}$ Group. (Table 2)

The Means \pm Standard Deviations of $\mathbf{R}_{\mathrm{a}}$ for the effect of the Reuse/Sterilization Cycle within each Polisher system group are graphically illustrated (Fig. 3), as well as the effect of the Polisher system within each Reuse/Sterilization Cycle group (Fig. 4). The important finding here is that although the $\mathbf{G}$ Group is showing the least $\mathbf{R}_{\mathbf{a}}$ values within the first two cycles, yet it showed the highest $\mathbf{R}_{\mathrm{a}}$ in the third, fourth, fifth cycles. Indicating a remarkable drop in the polishing tip efficiency. While both $\mathrm{D}$ and $\mathrm{O}$ groups maintained their performance in a better manner (Fig. 4).

TABLE (2) Two-way ANOVA followed by PostHoc test for the effect of Polisher type, sterilization and use time and their interaction on the surface roughness of resin composite.

\begin{tabular}{|c|c|c|c|c|c|c|}
\hline \multirow{2}{*}{$\begin{array}{c}\text { Polisher } \\
\text { system }\end{array}$} & \multicolumn{2}{|c|}{ Dimanto } & \multicolumn{2}{c|}{ ProGloss } & OptraPol & P-value \\
\cline { 2 - 7 } & $106.95^{\mathrm{b}}$ & \multicolumn{2}{|c|}{$112.54^{\mathrm{c}}$} & \multicolumn{2}{|c|}{$100.08^{\mathrm{a}}$} & 0.0001 \\
\hline $\begin{array}{c}\text { Use and } \\
\text { Steriliza- } \\
\text { tion }\end{array}$ & $\mathbf{S 1}$ & $\mathbf{S 2}$ & $\mathbf{S 3}$ & $\mathbf{S 4}$ & $\mathbf{S 5}$ & P-value \\
\cline { 2 - 7 } & $85.80^{\mathrm{a}}$ & $88.23^{\mathrm{a}}$ & $106.71^{\mathrm{b}}$ & $119.41^{\mathrm{c}}$ & $132.47^{\mathrm{d}}$ & 0.0001 \\
\hline
\end{tabular}

Same lower case superscript letter on each row indicates non statically significant difference at $(\mathbf{P}<\mathbf{0 . 0 5})$

The Control Group had the least statically significant surface roughness average $(71.3 \mathrm{~nm})$. All the first Reuse/Sterilization Cycle Groups (GS1, OS1, DS1) as well as, two of the second Reuse/Sterilization Cycle groups (GS2, OS2), gave higher $\mathrm{R}_{\mathrm{a}}$ without statistically significant difference between them or between them and the control group. While, the GS4, GS5, DS5, and Roughened Groups $(132.6 \mathrm{~nm})$, showed the highest $\mathrm{R}_{\mathrm{a}}$ without statistically significant difference between them (Fig. 5).

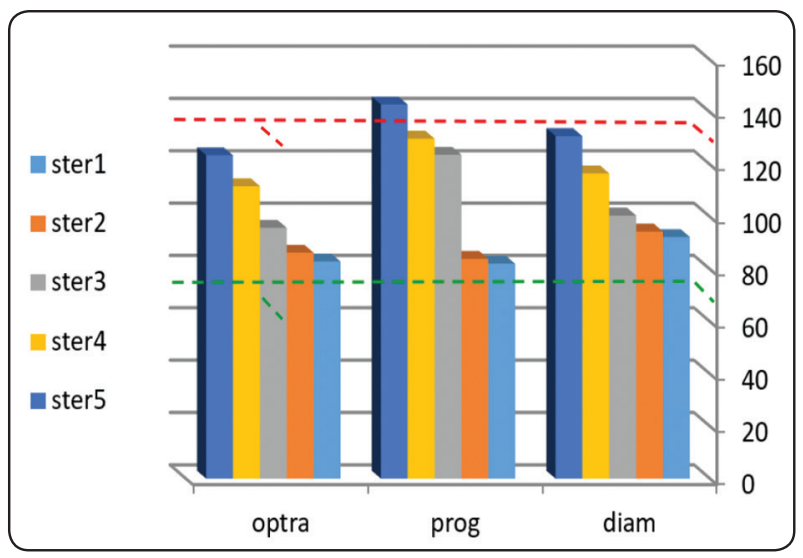

Fig. (3) A diagram showing the Means \pm Standard Deviations of $\mathrm{R}_{\mathrm{a}}$ for the effect of the Reuse and Sterilization Cycle within each Polisher system group.

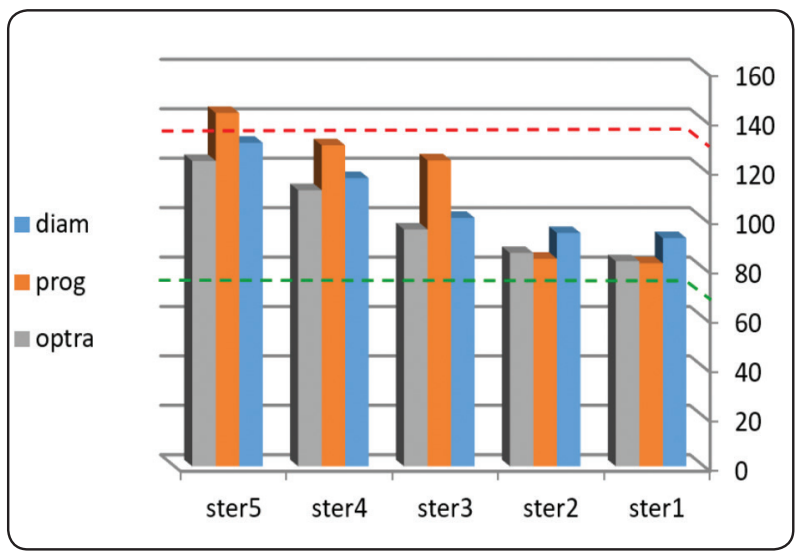

Fig. (4) A diagram showing the Means \pm Standard Deviations of $\mathrm{R}_{\mathrm{a}}$ for the effect of the Polisher system within each Reuse and Sterilization Cycle group. 


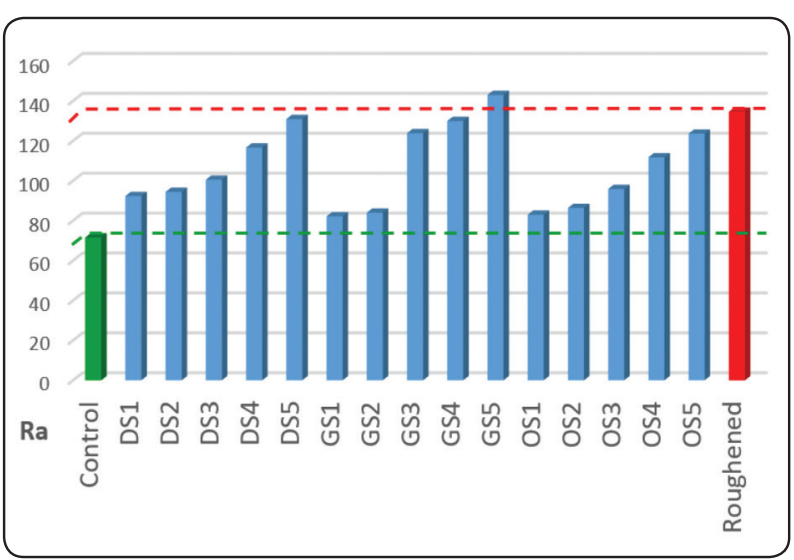

Fig. (5) One-way ANOVA test for $\mathrm{R}_{\mathrm{a}}$ followed by Dunnett Post Hoc test of all tested groups in comparison to Control $(71.6 \mathrm{~nm})$.

\section{DISCUSSION}

In this study, results showed that the Polisher system had a statistical significant effect on the surface roughness average $\mathbf{R}_{a}$, which consents with many other studies conducted on resin composite surface roughness. ${ }^{19-2425}$ While, regardless of the Reuse/Sterilization Cycle, the OptraPol Group showed the least statistically significant $\mathrm{R}_{\mathrm{a}}$ followed by the Dimanto Group, then the ProGloss Group. These variations in roughness average results between the different polishing systems in spite of being part of the same multi-use single-step polishers' category conforms with Wheeler et al. ${ }^{26}$ results on 2020 where the effects of five different two-step diamond impregnated polishing systems on the surface roughness and morphology of composite resin material was evaluated as they concluded their research that "Similarly designed polishing systems do not produce comparable surface roughness levels." The $R_{a}$ variations may be caused by the unequal distribution of abrasives in the delivery medium ${ }^{7}$, or the difference in abrasive diamond particles $\operatorname{size}^{27}$ a factor that was found to affect the polishing system efficiency by Bashetty et al. $^{7}$ where the fine diamond particles tips gave a much less roughness averages of the composite surface than the larger sized aluminum oxide particles polishing disks. Another trial to explain the variation in roughness average values between different polishing brands was conducted by Wang et al. ${ }^{24}$, in which the effects of abrasive particle shape, grit and distribution features on surface roughness were considered. The abrasive particle protrusion heights and indentation depth on the surface of rubber matrix were evaluated, and they found that reducing the height of abrasive particles protrusion on the polishing tip surface decreases resultant roughness of the composite surface..$^{24}$

Reuse and Sterilization Cycle also had a statistical significant effect on the $\mathbf{R}_{\mathrm{a}}$, and regardless to the Polisher system, $\mathbf{S} 1$ and $\mathbf{S} 2$ groups showed the least statically significant $\mathbf{R}_{\mathrm{a}}$, followed by $\mathbf{S 3}$ groups, $\mathbf{S} 4$ groups, and finally $\mathbf{S 5}$ groups with the highest $\mathbf{R}_{\mathrm{a}}$ with statistically significant difference between each one of the last three cycles and its following cycle. This actually conforms with Heintze \& Forjanic et al. ${ }^{16}$ on their study on polishing performance of multi-use silicone rubber-based polishing instruments with/without disinfection and sterilization where the material loss of the composite specimens and polishing instruments were measured. They found that already after the first use, the instruments which were used without disinfection or sterilization demonstrated a statistically significantly reduced polishing performance in all polishing steps compared to the new polishing system. In addition, this loss in performance further increased with the second and third re-use. By contrast, the multiple-use of the instruments which were subjected to prolonged chemical disinfection only did not result in a reduced polishing performance, but, was accompanied by an increased loss of the silicone rubber material of the polishing discs and adherence of particles of the rubber material to the composite. ${ }^{16}$

This decrease in the polishing performance of the silicon rubber tips after multiple autoclave sterilization cycles may be explained by the 
fact that the tensile strength and tear strength of the autoclaved silicon material was found to be significantly lower than those of the non-autoclaved ones by Apinhasmit et al..$^{28}$ as well as many high heat generated physical changes in the silicon matrix material ${ }^{12,14,29}$, which may lead to easier and faster loss of the abrasive particles from the surface of polishing tips in addition to accelerated wear of the tips surface itself, affecting their performance cycle after the other. Additionally, Shah \& Patel et al. ${ }^{30}$ concluded their study about the effect of sterilization on several types of rubber elastomers that even though no significant change has been found in physical and chemical criteria, yet, the surface hardness has slightly increased with steam sterilization and that the changes also depend upon the type of compound and type of elastomer used, as these results may vary from compound to compound due to type of elastomer used, curing agent or curing system used, processing parameters, time and number of autoclave and washing cycle done.

On the contrary, Lacerda V. et al. ${ }^{31}$ reported that the polishing kits used in their study at 2015 were sterilized/disinfected with an autoclave or peracetic acid at least five times without changing the performance, superficial composition, or morphological aspects, nevertheless, the polishing capacity on his study was evaluated with a (Talyscan 150 3Di surface scanning system) equipped with a contact probe, and the 3D scanning parameter measured was $\mathrm{Sa}$ (arithmetic mean roughness), but the data were presented in micrometer not nanometer, which might explain the statistically insignificant Sa values upon the five sterilization and use cycles. But it is important to note that Lacerda V. et al. ${ }^{31}$ also stated that when the surface of the points was analysed on SEM (150x) before and after the five cycles of polishing and sterilization, visible changes from the initial appearance (unused) was noticed, probably caused by the loss of the superficial layer, richer in polymer and with less filler particles exposed, in all the groups, after use.
Control group (cured against Mylar strip) showed the least statistically significant surface roughness average $\mathbf{R}_{\mathrm{a}}$, a fact that was compatible with many other studies where the Mylar/celluloid strip was used as a control guide for the lowest surface roughness ${ }^{1,32-34}$. However, it was also found that all the first Reuse/Sterilization Cycle Groups (GS1, OS1, DS1) as well as, two of the second Reuse/Sterilization Cycle groups (GS2, OS2), even though showing higher $\mathbf{R}_{\mathrm{a}}$ values than Control group, yet there was no statically significant difference neither between them nor between them and the control group $(71.3 \mathrm{~nm})$. In addition, these groups SEM scans showed a very smooth, wellpolished, and homogenous resin composite surface (Fig.1,2). Hence, this finding emphasize on the importance of polishing the resin composite surface to gain the optimum serviceability and durability of the restorations, but without forgetting that this result was only attainable within the first and second Reuse/Sterilization cycles and the resulting $\mathbf{R}_{\mathrm{a}}$ of the studied systems increased significantly after that. And this finding is totally consistent with Heintze S.et al..$^{16}$ previously mentioned work where the polishing performance dropped significantly after the first use. On the other hand, some of the fourth and fifth Reuse/Sterilization Cycle groups (GS4, DS5, GS5) showed a very high $\mathbf{R}_{\mathrm{a}}$, with no statistically significant difference between them and the Roughened group (132.6 nm), Indicating that their use was kind of impractical and useless Actually, the GS5 group $\mathbf{R}_{\mathrm{a}}$ value was slightly higher than the roughened group (Negative control), which means that the surface of resin composite samples wasn't affected at all (fig. 3).

Finally, the selection of Surface Roughness Average $\mathbf{R}_{\mathbf{a}}$ was based on the fact that it is the most important parameter to describe materials' topography ${ }^{22,35}$. And even though stylus-based devices are still dominating the surface roughness measurement task, stylus techniques have great 
inherent limitations as they were originally intended to acquire 2D surface topography. Therefore, 3D surface roughness data can only be obtained from stylus equipment executing multiple scans of the surface. This task takes a lot of time to achieve a satisfactory result, and may cause micro-scratches on the surfaces of the sample deteriorating it. Thus, shifting to other recent devices as AFM, SEM, optical microscopy, and laser profilometry was a must. When a comparison was done to compare these four different analysing techniques ${ }^{36}$. It was found that optical microscopy is a very efficient technique, as it yields information that SEM and AFM imaging are not able to provide (The roughness measurements complements the image data and gives quantitative information about height differences.) but they lack the resolution needed to see small nanometer scale variations. On contrary to AFM and SEM that can be used successfully to visualize the nanoscale details. ${ }^{36}$ AFM scans represents the roughness data of only a small part of the surface and therefore other methods like laser profilometer are needed to provide a larger scale description of the samples surface. So eventually, and even with regard to the high accuracy of the AFM, the limited field of assessment and lack of feasibility gave the heavier weight to the use of SEM in this study. The surface of the samples were scanned by SEM using the backscattered electron (BSE) detector and viewed on computer representing the basic $2 \mathrm{D}$ topography of the resin composite at $3000 \mathrm{x}$ magnification ${ }^{37}$ on which Gwyddion 2.53, was used for obtaining the surface roughness parameters from a 3D reconstruction model of surfaces using the SEM (BSED) scans based on stereo-vision concept ${ }^{2,38}$. This newly developed roughness analysing method using SEM scans visualized surface roughness by giving detailed roughness maps, which showed local variations in surface roughness values. This method provided us with a picture of the surface heterogeneity as well as the scale of the roughness ${ }^{36}$.

\section{CONCLUSION}

Under the limitations of this study, it could be concluded that single-step polishing tips can polish resin composite to matrix-set surface roughness average $\mathrm{Ra}$ values, within the first two Use/ Sterilization cycles, afterwards the tips polishability decreases and becomes system dependent.

\section{CONFLICT OF INTEREST}

The authors declare that they have no conflict of interest regarding the materials used in this study.

\section{REFERENCES}

1. Gedik R, Hürmüzlü F, Coşkun A, Bektaş ÖÖ, Özdemir AK. Surface roughness of new microhybrid resin-based composites. J Am Dent Assoc. 2005;136(8):1106-1112. doi:10.14219/jada.archive.2005.0314

2. Baroudi K, Kaminedi R, Penumatsa N, Priya T. The influence of finishing/polishing time and cooling system on surface roughness and microhardness of two different types of composite resin restorations. J Int Soc Prev Community Dent. 2014;4(5):99. doi:10.4103/2231-0762.146211

3. Erdemir U, Sancakli HS, Yildiz E. The effect of one-step and multi-step polishing systems on the surface roughness and microhardness of novel resin composites. Eur J Dent. 2012;6(2):198-205. doi:10.1055/s-0039-1698951

4. Jefferies SR. Abrasive Finishing and Polishing in Restorative Dentistry: A State-of-the-Art Review. Dent Clin North Am. 2007;51(2):379-397. doi:10.1016/j.cden.2006.12.002

5. Lassila, Lippo ; Eija Säilynoja ; Roosa Prinssi PKV and SG. The effect of polishing protocol on surface gloss of different restorative resin composites. Biomater Investig Dent. 2020;7(1):1-8. doi:10.1080/26415275.2019.1708201

6. Berger SB, Palialol ARM, Cavalli V, Giannini M. Surface roughness and staining susceptibility of composite resins after finishing and polishing. J Esthet Restor Dent. 2011;23(1):34-43. doi:10.1111/j.1708-8240.2010.00376.x

7. Bashetty K, Joshi S. The effect of one-step and multistep polishing systems on surface texture of two different resin composites. J Conserv Dent. 2010;13(1):34. doi:10.4103/0972-0707.62637

8. Alfawaz Y. Impact of polishing systems on the surface roughness and microhardness of nanocomposites. 
J Contemp Dent Pract. 2017;18(8):647-651 . doi:10.5005/ jp-journals-10024-2100

9. Baltacıoğlu IH, Irmak O, Ulusoy N, Cengiz E, Bağış YH. Comparison of One-Step and Multistep Polishing Systems for the Surface Roughness of Resin Composites. Open J Stomatol. 2016;06(03):73-80. doi:10.4236/ ojst.2016.63009

10. Healy CM, Kearns HPO, Coulter WA, Stevenson M, Burke FJT. Autoclave use in dental practice in the Republic of Ireland. Int Dent J. 2004;54(4):182-186. doi:10.1111/ j.1875-595X.2004.tb00278.x

11. Laneve E, Raddato B, Dioguardi M, Di Gioia G, Troiano G, Lo Muzio L. Sterilisation in dentistry: A review of the literature. Int J Dent. 2019;2019. doi:10.1155/2019/6507286

12. R.B. Simpson. Rubber Basics.; 2002.

13. Paul Ducheyne, Kevin Healy, Dietmar W. Hutmacher, David W. Grainger CJ. Comprehensive Biomaterials - Volume 1 -. Elsevier, Aug 28, 2015 - Technol Eng. 2015;1:135.

14. Park J, Lakes RS. Biomaterials: An Introduction: Third Edition.; 2007. doi:10.1007-978-0-387-37880-0

15. Forgas LB, Durland BJ, Duncanson MG, Parker DE. Effectiveness of four sterilizing procedures on prophylaxis cups. Am J Dent. 1990;3(6):245-248.

16. Heintze SD, Forjanic M. Polishing performance of multiple-use silicone rubber-based polishing instruments with and without disinfection/sterilization. Am J Dent. 2008;21(5):288-294.

17. Krejci I, Lutz F, Boretti R. Article Resin composite polishing--filling the gaps. Quintessence Int. 1999; 30(7):490-495.

18. Tate WH, Goldschmidt MC, Powers JM. Performance of composite finishing and polishing instruments after sterilization. Am J Dent. 1996;9(2):61-64.

19. Erdemir U, Yildiz E, Eren MM, Ozsoy A, Topcu FT. Effects of polishing systems on the surface roughness of tooth-colored materials. J Dent Sci. 2013;8(2):160-169. doi:10.1016/j.jds.2012.05.007

20. Caglar I, Ates SM, Duymus ZY. The effect of various polishing systems on surface roughness and phase transformation of monolithic zirconia. J Adv Prosthodont. 2018;10(2):132-137. doi:10.4047/jap.2018.10.2.132

21. Patel B, Chhabra N, Jain D. Effect of different polishing systems on the surface roughness of nano-hybrid compos- ites. J Conserv Dent. 2016;19(1):37-40. doi:10.4103/09720707.173192

22. Pettini F, Corsalini M, Savino MG, et al. Roughness Analysis on Composite Materials (Microfilled, Nanofilled and Silorane) After Different Finishing and Polishing Procedures. Open Dent J. 2015;9(1):357-367. doi: $10.2174 / 1874210601509010357$

23. De Oliveiraa ALBM, Garciab PPNS, Dos Santosc PA, Campos JÁDB. Surface roughness and hardness of a composite resin:Influence of finishing and polishing and immersion methods. Mater Res. 2010;13(3):409-415. doi:10.1590/s1516-14392010000300021

24. Wang G, Zhou X, Meng G, Yang X. Modeling surface roughness for polishing process based on abrasive cutting and probability theory. Mach Sci Technol. 2018;22(1):8698. doi:10.1080/10910344.2017.1336629

25. Riccardo Beltrami, Matteo Ceci, Gabriele De Pani, Lodovico Vialba, Ricaldone Federico CP et al. Effect of different surface finishing/polishing procedures on color stability of esthetic restorative materials: A spectrophotometric evaluation. Eur J Dent. 2018;12(1):49-56. doi:10.4103/ejd.ejd

26. Wheeler J, Deb S, Millar BJ. Evaluation of the effects of polishing systems on surface roughness and morphology of dental composite resin. Br Dent J. 2020;228(7):527532. doi:10.1038/s41415-020-1370-8

27. Hutchings IM, Xu Y, Sánchez E, Ibáñez MJ, Quereda MF. Development of surface finish during the polishing of porcelain ceramic tiles. J Mater Sci. 2005;40(1):37-42. doi:10.1007/s10853-005-5684-3

28. Apinhasmit W, Limsombutanon S, Swasdison S, Suppipat N. Effects of autoclave sterilization on properties of dental rubber dam as related to its use as barrier membrane in guided tissue regeneration. J Periodontal Res. 2003;38(5):538542. doi:10.1034/j.1600-0765.2003.00693.x

29. Gautriaud E, Stafford KT, Adamchuk J, Simon MW, Ou DL. Effect of Sterilization on the Mechanical Saint-Gobain Performance Plastics White Paper. 2009:1-8.

30. Shah N, Patel PNM. Effect of Sterilization on Elastomeric components Used in Pharmaceutical Industry. 2013;1(3):524-526.

31. Lacerda VA, Pereira LO, Hirata R, Perez CR. Evaluation of two disinfection/sterilization methods on silicon rubber-based composite finishing instruments. Am J Dent. 2015;28(6):337-341. 
32. Baroudi K, Hassan A, Nabih S, Mossa H. The effect of three polishing systems on surface roughness of flowable, microhybrid, and packable resin composites. J Int Soc Prev Community Dent. 2015;5(3):242. doi:10.4103/22310762.159965

33. St.-Georges AJ, Bolla M, Fortin D, Muller-Bolla M, Thompson JY, Stamatiades PJ. Surface finish produced on three resin composites by new polishing systems. Oper Dent. 2005;30(5):593-597.

34. Chour R, Moda A, Arora A, Arafath M, Shetty V, Rishal Y. Comparative evaluation of effect of different polishing systems on surface roughness of composite resin: An in vitro study. J Int Soc Prev Community Dent. 2016;6(8):S166S170. doi:10.4103/2231-0762.189761
35. Hossam AE, Rafi AT, Ahmed AS, Sumanth PC. Surface topography of composite restorative materials following ultrasonic scaling and its Impact on bacterial plaque accumulation. An in-vitro SEM study. J Int oral Heal JIOH. 2013;5(3):13-19.

36. Seitavuopio P. The Roughness and Imaging Characterisation of Different Pharmaceutical Surfaces. Vol 2.; 2006. http://ethesis.helsinki.fi/.

37. Jannah R, Thahar B, Mardiati E, Evangelina IA. Evaluation of surface roughness of the bracket slot before and after burning. Maj Kedokt Gigi Indones. 2019;4(2):102. doi:10.22146/majkedgiind.28387

38. Londono JCH. Surface roughness estimation by 3D stereo SEM reconstruction. 2015:70. 